\title{
Screening of maize germplasm for Turcicum leaf blight resistance
}

\author{
T. A. Wani ${ }^{1 *}$, G. N. Bhat ${ }^{1}$, Mushtaq Ahmad ${ }^{1}$, A. Anwar ${ }^{1}$ and Gul Zaffar ${ }^{2}$ \\ ${ }^{1}$ Division of Plant Pathology, Sher-e-Kashmir University of Agricultural Sciences \& Technology of Kashmir \\ (SKUAST-K), Shalimar, Srinagar-190025 (J\&K), INDIA \\ ${ }^{2}$ Division of Plant Genetics and Breeding, SKUAST-K Shalimar, Srinagar-190025(J\&K), INDIA \\ *Corresponding author. E-mail: tnvrwani@gmail.com \\ Received: July 19, 2017; Revised received: August 6, 2017; Accepted: January 15, 2018
}

\begin{abstract}
A study was conducted during Kharif 2012 and 2013 at Sher-e-Kashmir University of Agricultural Sciences and Technology of Kashmir, Shalimar Campus Srinagar with the objective of screening sixty maize genotypes against Turcicum leaf blight caused by Exserohilum turcicum (Pass.) Leonard and Suggs. Field experiment was laid out in a randomized block design with three replications. In order to ensure establishment of infection, artificial inoculation of E. turcicum on test genotypes was made twice at 30 and 40 days after sowing with two different methods of inoculation (spraying on foliage of maize with spore suspension of pathogen @ $5 \times 10^{4}$ spores $/ \mathrm{ml}$ at 30 DAS and by whorl drop inoculation of pathogen multiplies on sorghum grains at $40 \mathrm{DAS}$ ). Disease severity on test entries was scored at silk drying stage and studies revealed that two inbred lines, viz., NAl-112 and NAl-147, and one hybrid, viz., HQPM-1 were found resistant with pooled disease intensity of 4.12 per cent, 4.04 per cent and 4.38 per cent, respectively. Four inbred lines, viz., KDM 381 A, KDM 918 A, NAI-152 and NAI-167 were found susceptible with pooled disease intensity of 52.82 per cent, 51.02 per cent, 58.58 per cent and 61.33 per cent, respectively. The remaining genotypes were moderately resistant to moderately susceptible.
\end{abstract}

Keywords: Disease severity, Exserohilum turcicum, Maize, Screening, Turcicum leaf blight

\section{INTRODUCTION}

Maize (Zea mays L.) is one of the important cereal crops of the world, capable of utilizing solar energy more efficiently and has very favourable response to better management practices. Total world production of maize is 1033.80 million tonnes from total cultivated area of 184.80 million hectares and as such the average world productivity of maize is 5.61 tonnes/ hectare. United states of America ranks first in production and productivity of maize $(361.09 \mathrm{mt}$ and $10.73 \mathrm{t} / \mathrm{ha}$, respectively) followed by China (215.81 mt and $5.80 \mathrm{t} /$ ha, respectively). India ranks sixth in total maize production $(23.67 \mathrm{mt})$ from total cultivated area of 9.25 mha and as such our national productivity is $2.55 \mathrm{t} / \mathrm{ha}$ (FAOSTAT 2014). The productivity of maize in Jam$\mathrm{mu}$ and Kashmir is $1.65 \mathrm{t} / \mathrm{ha}$, which is lower than national average. Further Kashmir region has much lower productivity of $1 \mathrm{t} / \mathrm{ha}$ than Jammu region having $1.80 \mathrm{t} /$ ha (Anonymous 2013). Turcicum leaf blight is a major foliar disease of maize caused by Exserohilum turcicum (Pass.) Leonard and Suggs. The pathogen and the disease were first reported by Passerini (1876) from Perma, Italy. Luttrell (1957) described the perfect stage of the fungus as Trichometaspheria turcica. Leonard and Suggs. (1974) established the genus Exserohilum turcicum for Helminthosporium species in which the conidial hilum was strongly protuberant. They also placed the ascigerous (perfect) state of $E x$ serohilum in the new genus Setosphaeria. The causal agent of Turcicum leaf blight of maize is normally identified by its imperfect stage Exserohilum turcicum. It is a heterothallic facultative parasitic fungus (Luttrell, 1957). It reproduces both sexually and asexually, the sexual/perfect stage rarely occurs in nature but in the laboratory it may occur as black, globose pseudothecia. This disease is popularly known as Northern Corn Leaf Bight (NCLB) in the United States of America. The disease is favoured by mild temperature and high humidity (Ullstrup, 1970). Heavy dews, cool temperature and frequent rains are environmental conditions conducive for disease development (Jordan et al., 1983). Mid-altitude regions, about $900-1600 \mathrm{~m}$ above sea level, have particularly favourable climate for the disease as dew periods are long and temperature moderate. Ogliari et al. (2005) described that temperature between $20^{\circ} \mathrm{C}$ and $25^{\circ} \mathrm{C}$, relative humidity from 90 to 100 per cent and low luminosity favour the disease. Welz and Geiger (2000) described that symptoms of the disease can range from small cigar-shaped lesions to complete destruction of the foliage. In India, the disease was first reported by Butler in 1907 from Bihar. The disease is reported to have appeared in an 
epiphytotic form in the Kashmir valley during 1956-57 (Koul, 1957). Chenula and Hora (1962) studied loss due to the disease in Shimla, Himachal Pradesh and recorded 16.6 to 68.7 per cent loss in yield of green weight and 27.6 to 90.7 per cent loss in grain yield of maize. Babu et al. (2004) reported severe incidence of Turcicum leaf blight of maize in Uttarakhand, attaining epidemic proportions which resulted in 83 per cent yield reduction. The disease has attained economic status in Jammu and Kashmir. Host plant resistance is considered as most practical, feasible, cheapest and most effective way to control leaf blight diseases because chemical treatments are expensive, often ineffective, and sanitation practices in crops such as maize are difficult to apply. Hence study was carried out to screen the maize germplasm under artificial inoculated conditions for resistance to the disease.

\section{MATERIALS AND METHODS}

Sixty genotypes of maize collected from Karewa Damodor Research Station, Sher-e-Kashmir University of Agricultural Sciences \& Technology of Kashmir, were screened in field under artificially inoculated conditions for disease development during kharif 2012 and 2013 at Shalimar campus, Srinagar of SKUAST$\mathrm{K}$. The seeds were sown in a randomized block design with $3 \mathrm{~m} \times 2 \mathrm{~m}$ plot size, spaced at $75 \mathrm{~cm} \times 20 \mathrm{~cm}$ and replicated thrice. Recommended agronomic practices and insect pest control measures were followed as per the package of practice of Sher-e-Kashmir University of Agricultural Sciences \& Technology of Kashmir (Anonymous, 2011). Fifteen days old pure culture of E. turcicum multiplied on Potato dextrose agar (PDA) medium was used for artificial inoculation of genotypes at 30 days after sowing (DAS). The spore suspension prepared in sterilized distilled water having spore load of $5 \times 10^{4}$ spores per ml was sprayed with atomizer on foliage of maize genotypes. Further at 40 DAS whorl drop inoculation of plants was done with E. turcicum multiplied on sorghum grains to ensure the establishment of infection. The inoculations were done in the evening. A light water spray was given $24 \mathrm{~h}$ after both inoculations to create optimum humidity for infection. The disease severity on the test entries was scored at silk drying stage using 1-5 disease rating scale as shown in the table 1 (James, 1971).

\section{RESULTS AND DISCUSSION}

Table 1. Disease rating scale.

\begin{tabular}{lll}
\hline $\begin{array}{l}\text { Disease } \\
\text { rating } \\
\text { scale }\end{array}$ & $\begin{array}{l}\text { Per cent dis- } \\
\text { ease severity }\end{array}$ & Disease reaction \\
\hline 1. & $0.1-10.0$ & Resistant (R) \\
2. & $10.1-25.0$ & Moderately Resistant (MR) \\
3. & $25.1-50.0$ & Moderately Susceptible (MS) \\
4. & $50.1-75.0$ & Susceptible (S) \\
5. & Above 75 & Highly Susceptible (HS) \\
\hline
\end{tabular}

Results of the present study revealed that none of the tested genotypes observed was completely free from Turcicum leaf blight infection. However, significant variations in disease severity index for the disease were observed in various genotypes. The observed disease intensity varied from low (1) to very severe (5) in all the tested genotypes. Among the sixty genotypes screened, only three genotypes were registered as resistant (R), twenty-five genotypes were rated as moderately resistant (MR), twenty-eight genotypes expressed as moderately susceptible (MS), whereas, four genotypes were found susceptible (S) (Table-2 and Table-3). Among the six SKUAST-K released varieties only one variety, i.e., Shalimar C4 was rated as moderately resistant, however, the other five released varieties, viz., C6, C15, C8, C14 and Super-I were rated as moderately susceptible. Among the forty-three inbred lines, only two inbreds viz., NAI-112 and NAI-147 registered resistant reaction, sixteen inbreds were rated as moderately resistant and twenty one inbreds expressed moderately susceptible reaction. However, four inbred lines, i.e., KDM 381 A, KDM 918 A, NAI152 and NAI-167 were severely affected by Turcicum leaf blight and rated as susceptible. Among the eleven private hybrids only one hybrid, i.e., HQPM-1 was found promising with the resistant reaction, eight hybrids registered moderately resistant reaction. The remaining two hybrids, viz., 30V92 and NK6607 were moderately susceptible.

Inherent resistance or tolerance of plants to infection by pathogen is the most economic and ecofriendly disease management venture. Resistance to E. turcicum in maize germplasm was previously reported (Muriithi and Mutinda, 2001; Pandurangegowda et al., 2002). Kumar et al. (2011) identified twenty inbred lines as sources of resistance against Turcicum leaf blight of maize. Shikari and Zafar (2009) reported that inbred NAI-147 and composite Girija expressed reisitance to Turcicum leaf blight. Ahangar et al., 2016 screened sixty genotypes of maize against $E$. turcicum under artificially inoculated field conditions and found twenty six genotypes as resistant and moderately resistant. Further, they screened these twenty six genotypes of maize against twelve isolates of E. turcicum under artificial epiphytotic conditions and found eight genotypes as resistant and eight as moderately resistant.

\section{Conclusion}

The use of resistant varieties is most feasible and practical measures of managing Turcicum leaf blight of maize. The inbred lines viz., NAI-112 and NAI-147 identified to possess resistance to Turcicum leaf blight of maize in the present study, can be used successfully in developing high yielding early maturing varieties for the temperate hill region having high level of re- 
T. A. Wani et al. / J. Appl. \& Nat. Sci. 10 (1): 98 - 101 (2018)

Table 2. Screening of maize germplasm for Turcicum leaf blight resistance under field conditions during 2012 and 2013.

\begin{tabular}{|c|c|c|c|c|c|}
\hline \multirow[t]{2}{*}{ S. No. } & \multirow[t]{2}{*}{ Genotype } & \multicolumn{3}{|c|}{ Disease intensity* } & \multirow{2}{*}{$\begin{array}{l}\text { Disease } \\
\text { score }\end{array}$} \\
\hline & & 2012 & 2013 & Pooled Mean & \\
\hline 1. & C 6 & $33.29(35.24)$ & $35.42(36.52)$ & $34.36(35.88)$ & 3 \\
\hline 2. & C 15 & $34.59(36.02)$ & $39.37(38.86)$ & $36.98(37.45)$ & 3 \\
\hline 3. & C 8 & $27.21(31.44)$ & $29.55(32.93)$ & $28.38(32.19)$ & 3 \\
\hline 4. & C 14 & $37.62(37.83)$ & $41.14(39.90)$ & $39.38(38.87)$ & 3 \\
\hline 5. & Shalimar C 4 & $14.75(22.58)$ & $16.68(24.10)$ & $15.71(23.35)$ & 2 \\
\hline 6. & Super 1 & $43.70(41.38)$ & $45.43(42.38)$ & $44.57(41.88)$ & 3 \\
\hline 7. & KDM 72 & $19.07(25.90)$ & $20.60(26.99)$ & $19.84(26.45)$ & 2 \\
\hline 8. & KDM 322 & $17.15(24.46)$ & $17.52(24.75)$ & $17.34(24.61)$ & 2 \\
\hline 9. & KD synthetic 1 & $18.15(25.21)$ & $19.37(26.11)$ & $18.76(25.67)$ & 2 \\
\hline 10. & KDM 1296 & $24.82(29.88)$ & $25.67(30.44)$ & $25.24(30.16)$ & 3 \\
\hline 11. & KDM 111 & $29.46(32.87)$ & $30.95(33.80)$ & $30.20(33.34)$ & 3 \\
\hline 12. & KDMH -21 & $15.26(22.99)$ & $17.13(24.45)$ & $16.19(23.73)$ & 2 \\
\hline 13. & Y 2 & $17.15(24.46)$ & $19.15(25.95)$ & $18.15(25.22)$ & 2 \\
\hline 14. & KDM 340 A & $24.61(29.74)$ & $27.64(31.72)$ & $26.13(30.74)$ & 3 \\
\hline 15. & KDM $930 \mathrm{~A}$ & $36.23(37.01)$ & $39.14(38.73)$ & $37.69(37.87)$ & 3 \\
\hline 16. & KDM 445 B & $18.06(25.15)$ & $21.31(27.49)$ & $19.69(26.34)$ & 2 \\
\hline 17. & KDM 332 A & $21.74(27.79)$ & $24.55(29.70)$ & $23.15(28.76)$ & 2 \\
\hline 18. & KDM 362 A & $43.47(41.25)$ & $45.08(42.17)$ & $44.27(41.71)$ & 3 \\
\hline 19. & KDM 914 A & $27.51(31.64)$ & $29.54(32.92)$ & $28.53(32.28)$ & 3 \\
\hline 20. & KDM 895 A & $38.05(38.09)$ & $39.44(38.91)$ & $38.75(38.50)$ & 3 \\
\hline 21. & KDM 892 A & $26.13(30.74)$ & $28.16(32.05)$ & $27.15(31.40)$ & 3 \\
\hline 22. & KDM 343 A & $25.59(30.39)$ & $30.54(33.55)$ & $28.06(31.99)$ & 3 \\
\hline 23. & KDM 916 A & $22.25(28.15)$ & $25.41(30.27)$ & $23.83(29.22)$ & 2 \\
\hline 24. & KDM 361 A & $31.4(34.08)$ & $33.65(35.46)$ & $32.53(34.77)$ & 3 \\
\hline 25. & KDM 925 B & $19.06(25.89)$ & $21.00(27.27)$ & $20.03(26.59)$ & 2 \\
\hline 26. & KDM $911 \mathrm{~A}$ & 32.89 (34.99) & $36.18(36.98)$ & $34.53(35.99)$ & 3 \\
\hline 27. & KDM 438 A & $15.33(23.05)$ & $16.42(23.90)$ & $15.87(23.48)$ & 2 \\
\hline 28. & KDM 932 A & $29.2(32.71)$ & $32.2(34.57)$ & $30.70(33.65)$ & 3 \\
\hline 29. & KDM 925 A & $39.14(38.73)$ & $41.35(40.02)$ & $40.24(39.37)$ & 3 \\
\hline 30. & KDM 381 A & $52.03(46.16)$ & $53.60(47.06)$ & $52.82(46.61)$ & 4 \\
\hline 31. & KDM 938 A & $32.69(34.87)$ & 36.19 (36.99) & $34.44(35.93)$ & 3 \\
\hline 32. & KDM 344 A & $38.06(38.09)$ & $40.64(39.61)$ & $39.35(38.85)$ & 3 \\
\hline 33. & KDM $445 \mathrm{~A}$ & $20.93(27.22)$ & $23.41(28.93)$ & $22.17(28.09)$ & 2 \\
\hline 34. & KDM 924 A & $45.29(42.30)$ & $46.34(42.90)$ & $45.82(42.60)$ & 3 \\
\hline 35. & KDM 912 A & $33.27(35.23)$ & $36.04(36.90)$ & $34.66(36.07)$ & 3 \\
\hline 36. & KDM 945 A & $29.43(32.86)$ & $29.44(32.86)$ & $29.44(32.86)$ & 3 \\
\hline 37. & KDM 913 A & $41.01(39.82)$ & $43.24(41.12)$ & $42.13(40.47)$ & 3 \\
\hline 38. & KDM 918 A & $48.34(44.05)$ & $53.71(47.13)$ & $51.02(45.59)$ & 4 \\
\hline 39. & KDM $440 \mathrm{~A}$ & $19.10(25.91)$ & $21.87(27.88)$ & $20.48(26.91)$ & 2 \\
\hline 40. & NAI-104 & $22.49(28.31)$ & $23.37(28.91)$ & $22.93(28.61)$ & 2 \\
\hline 41. & NAI-112 & $03.70(11.09)$ & $04.54(12.31)$ & $04.12(11.71)$ & 1 \\
\hline 42. & NAI-113 & $21.55(27.66)$ & $22.91(28.59)$ & $22.23(28.13)$ & 2 \\
\hline 43. & NAI-123 & $29.45(32.87)$ & $31.81(34.33)$ & $30.63(33.60)$ & 3 \\
\hline 44. & NAI-143 & $14.49(22.38)$ & $16.29(23.81)$ & $15.39(23.10)$ & 2 \\
\hline 45. & NAI-147 & $03.37(10.59)$ & $04.70(12.53)$ & $4.04(11.59)$ & 1 \\
\hline 46. & NAI-152 & $57.28(49.18)$ & $59.89(50.70)$ & $58.58(49.94)$ & 4 \\
\hline 47. & NAI-155 & $17.13(24.45)$ & $18.54(25.51)$ & $17.84(24.98)$ & 2 \\
\hline 48. & NAI-161 & $34.29(35.84)$ & $35.72(36.70)$ & $35.01(36.27)$ & 3 \\
\hline 49. & NAI-167 & $60.41(51.01)$ & $62.24(52.08)$ & $61.33(51.55)$ & 4 \\
\hline 50. & DKC 7074 & $18.21(25.26)$ & $19.56(26.25)$ & $18.88(25.75)$ & 2 \\
\hline 51. & HQPM-1 & $03.56(10.89)$ & $05.20(13.19)$ & 04.38 (12.09) & 1 \\
\hline 52. & DKALB Double & $21.87(27.88)$ & $24.77(29.85)$ & $23.32(28.87)$ & 2 \\
\hline 53. & Pinnacle & $20.92(27.22)$ & $24.59(29.73)$ & $22.76(28.49)$ & 2 \\
\hline 54. & DKC 9108 & $22.43(28.27)$ & $24.25(29.50)$ & $23.34(28.89)$ & 2 \\
\hline 55. & DKC 9106 & $14.42(22.32)$ & $16.86(24.24)$ & $15.64(23.30)$ & 2 \\
\hline 56. & K 2020 & $21.45(27.59)$ & $24.25(29.50)$ & $22.85(28.55)$ & 2 \\
\hline 57. & $30 \mathrm{~V} 92$ & $29.02(32.60)$ & $32.18(34.56)$ & $30.60(33.58)$ & 3 \\
\hline 58. & P3501 & $19.11(25.92)$ & $21.86(27.87)$ & $20.48(26.91)$ & 2 \\
\hline 59. & NK6607 & $33.4(35.30)$ & $35.22(36.40)$ & $34.31(35.85)$ & 3 \\
\hline 60. & Swarna & $13.53(21.58)$ & $15.80(23.42)$ & $14.67(22.52)$ & 2 \\
\hline Overal & & $27.08(31.36)$ & $29.31(32.78)$ & $28.20(32.07)$ & \\
\hline $\mathrm{CD}(\mathrm{p} s$ & & 0.39 & 0.45 & 0.31 & \\
\hline
\end{tabular}

*Average of 3 replications, Figures in Parenthesis are arc sine transformed values 
Table 3. Reaction of maize germplasm for Turcicum leaf blight resistance.

\begin{tabular}{lll}
\hline Disease rating & Reaction & Maize genotype \\
\hline 1.0 & Resistant & NAI-112, NAI-147, HQPM-1 \\
2.0 & Soderately & KDalimar C4, KDM72, KDM322, \\
& resistant & KDM925B, KDM438A, KDM445A, KDM440A, NAI-104, NAI-113, NAI-143, \\
& & NAI-155, DKC7074, DKALB-Double, Pinnacle, DKC9108, DKC9106, K- \\
& 2020, P3501, Swarna. \\
3.0 & C6, C15, C8, C14, Super-1, KDM1296, KDM111, KDM340A, KDM930A, \\
& KDM362A, KDM914A, KDM895A, KDM892A, KDM343A, KDM361A, \\
& Susceptible & KDM911A, KDM932A, KDM925A, KDM938A, KDM344A, KDM924A, \\
4.0 & & KDM912A, KDM945A, KDM913A, NAI-123, NAI-161, 30V92, NK6607 \\
5.0 & KDM381A, KDM918A, NAI-152, NAI-167 \\
\hline
\end{tabular}

sistance to the disease.

\section{REFERENCES}

Ahangar, M. A., Bhat, Z. A., Sheikh, F. A., Dar, Z. A., Lone, A. A., Hooda, K. S. and Reyaz, M. (2016). Pathogenic variability in Exserohilum turcicum and identification of resistant sources to turcicum leaf blight of maize (Zea mays L.). Journal of Applied and Natural Science 8 (3): 1523-1529

Anonymous (2011). Cereal Crops (Kharif and Rabi) Package of Practices, Field Crops, SKUAST-Kashmir, 3:19-34

Anonymous (2013). Digest of Statistics 2012-13. Directorate of Economics and Statistics Govt. of J\& K.

Babu, R., Mani, V.P., Pandey, A.K., Pant, S.K., Kundu, R.S. and Gupta, H.S. (2004). Maize research at Vivekanand Parvatiya Krishi Anusandhan Sansthan - An Overview. Technical Bulletin, Vivekanand Parvatiya Krishi Anusandhan Sansthan, Almora, 21:31 (cf: Karnataka Journal of Agricultural Sciences 21(1): 55-60).

Butler, E.J. (1907). Some diseases of cereals caused by Selenorpel graminicola. Department of Agriculture, India. Botanical Survey. 2: 1-24.

Chenula, V.V. and Hora, T.S. (1962). Studies on losses due to Helminthosporium blight of maize. Indian Phytopathology 15: 235-237.

FAOSTAT, (2014). Food and Agriculture Organization of United Nations. www.fao.org.

James, W.C. (1971). An illustrated series of assessment keys for plant diseases, their preparation and usage. Canadian Plant Disease Survey 51: 39-65

Jordan, E.G., Perkins, J.M., Schall, R.A. and Pederson, W.L. (1983). Occurrence of race 2 of Exserohilum turcicum on corn in central United States. Plant Disease 67:1163 -1165 .

Koul, T.N. (1957). Out breaks and new records. Food and Agriculture Organization. Plant Protection Bulletin 5 (6): 93-96.

Kumar, S., Pandurangegowda, K.T., Pant, S.K., Shekhar, M.,
Kumar, B., Kaur, B., Chchi, K.H., Singh, O.N. and Parsanna, B.H. (2011). Sources of resistance to Exserohilum turcicum (Pass.) and Puccinia polysora (Underw.) incitant of Turcicum leaf blight and polysora rurt of maize. Archives of Phytopathology and Plant Protection 44 (6): 528-536.

Leonard, K.J. and Suggs, E.G. (1974). Setosphaeria prolata is the ascigenous state of Exserohilum prolata. Mycologia 66: 181-297.

Luttrell, E.S. (1957). Leptosphaeria (Metasphaeria) perfect stages for Helminthosporium turcicum and $H$. rostratum. Phytopathology 47: 313.

Muriithi, L.M. and Mutinda, C.J. (2001). Genetic variability of maize genotypes for resistance to Exerohilum turcicum in Kenya. In: Seventh Eastern and Southern Africa Regional Maize Conference, 106-109.

Ogliari, J.B., Guimaraes, M.A., Geraldi, I.O. and Camargo, L.E.A. (2005). New resistance genes in the Zea maysExserohilum turcicum pathosystem. Genetics and Molecular Biology 28 (3): 435-439.

Pandurangegowda, K.T., Naik, P., Setty, T.A.S., Hattappa, S., Naik, N.P. and Juna, M. (2002). High yielding maize composite NAC 6004 resistant to Turcicum leaf blight and downy mildew. Environment and Ecology 20: 920-923.

Passerini, (1876). Lanebbia Delgranotur Co. Bol. Comiz, Agriculture. Parmense 10: 3. (cf: Karnataka Journal of Agricultural Sciences 20 (3): 655-666).

Shikari, A.B. and Zaffar, G. (2009). Evaluation and identification of maize for Turcicum leaf blight resistance under cold temperate conditions. Maize Genetics Cooperation Newsletter Vol. 83.

Ullstrup, A.J. (1970). A comparison of monogenic and polygenic resistance to H. turcicum in corn. Phytopathology 60: 1597-1599.

Welz, H.G. and Geiger, H.H. (2000). Genes for resistance to northern corn leaf blight in diverse maize populations. Plant Breeding 119: 1-14. 